\title{
Article \#2
}

\section{The ethics of animal research: A neuroscientist's view}

\author{
Nicholas D. Vesprini, PhD (Candidate)
}

While important, discussions concerning the use of animals in scientific research are often repetitive and limited in scope and range. Such discussions seek to establish whether it is morally acceptable to use animals in research; however, a fuller assessment of the morality of animal research would require that all aspects of one's actions be examined. If the reasoning behind a number of commonly used arguments (e.g., the Greater Good argument) is applied beyond the context of scientific research and used in everyday life it becomes obvious that one cannot act in a morally consistent manner. I wish to emphasize the point that the use of animals in general is based on an all-or-none principal, and in most cases, actions taken to truly act morally are not possible. As such, all persons eventually reach a point where their morality is compromised on practical grounds.

On Animal Rights: One argument used to justify the use of animals in research has been "the Greater Good" argument. This position holds that the sacrifice of a few animals is warranted if it results in an overall benefit to society through the advancement of science. Such benefits are not restricted to human persons, but also extend to animals. Dissenters argue that a deontological approach* towards animal research is required, where the methods used to acquire scientific data should be a determining factor as to whether a research project is morally acceptable. Others argue that sacrificing an animal violates the rights of that animal. Therefore, any scientific insights or products generated using animals as experimental subjects are immoral by nature, since the discoveries have been made at the expense of the inherent rights of animals. If we extend this logic into everyday life it quickly becomes apparent that most of society is, at some level, acting immorally. For example, since the use of animals as a food source requires a sacrifice of livestock, we would be obligated to deem this act as morally unacceptable since it violates an animal's right to life. Despite a need for sustenance one would act immorally if he or she were to consume animal-based foods. Surely if the use of animals in research (arguably a "worthy" cause) is not socially acceptable, then satisfying one's dietary needs could be deemed a crime of selfishness and luxury. Despite the presence of alternative diets (i.e., vegan/vegetarian) it would appear that the vast majority of society readily and without conscience consumes animal-based foods. One could argue that society in general is unwilling to recognize the rights of animals, act in a truly moral manner and thus turns a blind eye towards the use of animals as a food source. This demonstrates the all-or-none principal I spoke of earlier, in which animals are either selectively used as we see fit, and thus are used immorally, or are left completely untouched and morally secure. While there may be a great deal of support against the general use of animals in research, I am uncertain whether society as a whole would welcome and embrace an alternative lifestyle simply to ensure conservation of our moral integrity.

Animal \& Higher Capacities: Another point that is often raised when arguing against the use of animals in research is that, in the pursuit of beneficial scientific knowledge, one must also consider the interests of the animals used (i.e., a consequentalistic approach**). Of particular concern is the use of animals which are sentient or possess characteristics of "higher" intelligence. The point that is emphasized here is that animals (typically mammals) which have the capacity to perceive pain, to learn and remember, to communicate or other similar abilities should be viewed differently from those which do not. The exploitation and sacrifice of these "higher" animals represents a grave moral infraction. As such, it is argued that animals which are endowed with such capacities should be excluded from the laboratories of animal researchers. Such thinking would imply that there is a ranking of animal species, whereby animals which posses some trait would be of more value than an animal which does not possess this trait. This line of reasoning leads to the question of whether it is moral to establish and enforce such distinctions. Is this not speciesism?*** One could argue that passing such judgment based on our own ideals and values would be an immoral act, as we would be comparing species to an artificial scoring of importance. Ironically, the advancement of scientific knowledge typically changes our view of even the "simplest" animals, often revealing greater complexity than had been previously thought. This alone highlights how any ranking system would be highly tentative, variable and inaccurate. It would seem that to be unbiased in our valuation of animal species one would be need to value all animals equally regardless of their supposed importance. Alternatively, if the moral value of animal species is based on some innate characteristic, one would also have to include all species which possess this trait. For example, many invertebrates have the capacity for learning and memory $^{1-3}$ as well as (chemical) communication ${ }^{4,5}$; thus, if we were to use a criterion to value animals based on the ability to learn, store memories and communicate, we would not only include mammals but also virtually all other 
organisms as well.

Having expanded our list of animals in need of moral protection in order to be truly moral ourselves, issues of practically arise which make everyday life unmanageable. If cockroaches and fruit flies are deemed worthy of moral consideration one would be forced to prohibit themselves from eradicating them from their homes. Driving one's car on a summer afternoon turns the windshield into a 'morality graveyard' with insect causalities that have been unjustly sacrificed for the driver's need to travel. At some point we have all killed animals which possessed some similar "saving quality" as the animals typically being passionately fought for by those who oppose animal use in research. The difference I am attempting to highlight here is that, for the sake of practically, we arbitrarily draw a line of moral duty above our victims so as not to feel immoral. Again, I would argue that an all-or-none principal is at work, whereby we either immorally value different animals based on their supposed importance (i.e., speciesism), or act truly morally and value all animals equally.

Animal Use - A Proposal: I have attempted to illustrate that implementing a truly moral position encompassing both research and other animal use is beyond the scope of practically. A truly moral position would require the exclusion of all animals from any use. This is simply not possible. Compromises are made at some point or another, making us all participants in the immoral use of animals. I would argue that rather than debate the ethical use of animals in research, we could better use available resources. Our sense of morality should drive us to make the best of a bad situation. If we accept that animals are inevitably sacrificed (for multiple uses) we can direct our concern to the handling and care of animals prior to their use. Since we cannot avoid sacrificing animals, we should shift our focus to animal welfare thereby ensuring that animals sacrificed in the name of science are treated respectfully and as humanely as possible.

* Deontological ethics is an approach which judges the morality of an act by reference to rules and duties.

** Consequentialism is an approach to ethics which judges the morality of an act based on the consequences which flow from it.

*** Speciesism is the ascription of differing value or rights to an animal based on its being a member of a particular species.

References:

1. Hochner B. (2010). Functional and comparative assessments of the octopus learning and memory system. Frontiers in Bioscience. 2:764-71.

2. Ardiel E.L., and Rankin C.H. (2010) An elegant mind: learning and memory in Caenorhabditis elegans. Learning \& Memor.y 17(4):191-201.

3. Srinivasan M.V. (2010) Honey bees as a model for vision, perception, and cognition. Annual Review of Entomology. 55:267-84.

4. Claudia B, Rita C, Stefano T.(2010). Pheromones in social wasps. Vitamins and Hormones. 83:447-92.

5. Ferveur JF.(2005). Cuticular hydrocarbons: their evolution and roles in Drosophila pheromonal communication. Behavioural Genetics. 35(3):279-95.

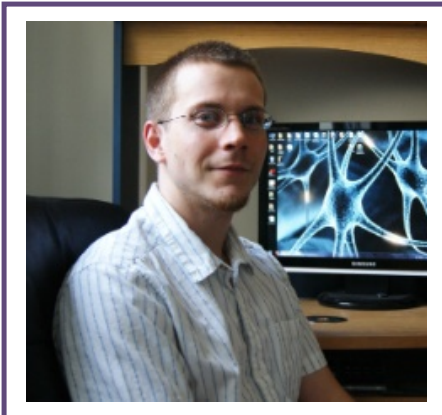

\section{Author Profile}

Nick Vesprini is currently a PhD student enrolled in Biological Sciences (Neurobiology and Physiology) at Brock University where he also completed his undergraduate studies. His research interests include neuronal regeneration, vitamin A, molecular biology and neurodegenerative diseases. 
Response to Vesprini on the Ethics of Animal Experimentation Vesprini addresses two common positions in his article - animals as possessors of rights and the ascription of moral value to animals on the basis of possessing certain higher functions. Yet, he does not so much critique these positions as trace their logic using a reductio ad absurdum approach. Apparently embracing these arguments he concludes that since animal use cannot practically be eliminated we must face the inevitable - the toleration of our own sustained immorality.

Yet, such a proposition seems deeply dissatisfying. If indeed animals are our moral equals, and possessors of rights, then we ought to treat them as such regardless of whether scientific progress would be impeded, or dietary adjustments required. If we would not use a child as an experimental subject, neither should we use a chimpanzee provided they are moral equals. Our moral duty would entail this. Where Vesprini errs is in his assent to the principle of moral equality between human persons and animals.

Animal Rights: First consider what it means to possess rights: "What matters in the having of rights is twofold: a) knowledge; b) freedom," writes philosopher D.S. Oderberg. "More precisely, a right holder must first know that he is pursuing a good, and secondly, must be free to do so. No one cannot be under a duty to respect another's right if he cannot know what it is he is supposed to respect. Similarly, no one can call another to account over respecting his right if the former cannot know what it is the latter is supposed to respect. By 'call to account' I mean making a conscious demand on them, even without speaking a word. How can a right holder make a conscious demand on another if he cannot know what he is demanding?"1 There is no strong evidence suggesting animals possess moral knowledge. They act instinctively and therefore inhabit an amoral universe. Animals are not moral agents, and consequently lack inherent rights. When we assign rights to animals we project uniquely human rights - based on our moral agency rooted in knowledge and freedom - into an amoral realm. As unique moral agents, we ought to consider our obligation to animals and their welfare, rather than projecting morality and rights into the amoral animal world.

The Ethical Use of Animals: Our shared history with the animal kingdom ought to make us sensitive to their welfare, but it should not obscure the factors which make human beings unique. To some this may be textbook 'speciesism'; I maintain it is a self-evident truth. Human beings are moral agents and possess rights; nonhuman animals are not. In contrast to the use of humans, animal use in biomedical research does not violate their 'rights.' Our moral duty to conduct research which maximizes human - and as a byproduct, animal - flourishing requires the use of animal subjects. 2 This being the case, it is also our moral duty, as Vesprini notes, to ensure proper care is provided for all animals used in experiments. I therefore conclude that when animals are treated humanely, no injustice is done when they are used to promote society's welfare.

\section{Reference}

${ }^{1}$ Cited in, Smith, W.J. (2010) A Rat is a Pig is a Dog is a Boy. The Human Cost of the Animal Rights Movements. Enounter Books. New York, NY., p.234

${ }^{2}$ The importance of animal research is questioned by many opponents of animal research. For an expose of this specious argument see, Conn, M.P., Parker, J.V. (2008) The Animal Research War. Palgrave MacMillan. New York, NY.

Nathan Farrar is a PhD candidate studying at the University of Alberta.

\section{Animal Experimentation: A Different Perspective}

Vesprini makes two bold declarations near the conclusion of his argument stating that "implementing a truly moral position encompassing research and animal use is beyond the scope of practicality" and that a "truly moral position would require the exclusion of all animals from any use". However, there is very little argument presented in the paper to support either one of these statements.

Several examples of moral stances relating to animal experimentation are discussed, and the impracticalities of some arguments against animal use are demonstrated. However, the practicalities of arguments in favour of animal use are not really acknowledged and no counter-arguments are presented. This relates to the second highlighted statement whereby the author does not really build a strong argument as to why the discontinuation of animal use is the moral of the two options, but merely provides examples of how this argument would be presented from different theories and methods of reasoning.

Animal use is a part of virtually every human culture, and it can even be argued that it is derivative of our human nature. To condemn animal use would be to absolve the future of drug development, and possibly retract the use of therapies already on the market.

Vesprini discusses the consequentialist viewpoint relating to arguments against animal use, and I do believe as a society we have chosen to view animal experimentation largely from this perspective, but instead because we value the products of animal experimentation as being justified and worthy of the consequences to lab animals. This is perpetuated by the fact that we have all experienced benefit (directly or indirectly) from a drug or treatment derived from animal testing.

The author questions the role of speciesism in our decisions, and it's clear that as a society we do subscribe to this notion as we uphold higher standards of living for humans versus other animals. Society may not view trivial human desires as superseding the vital needs of other species; however we do view it as being moral to choose the life of a human over that of many mice.

Society views science, research and the advancement of medicine as good things demonstrated by the number of major charities in support of disease research. Vesprini discusses deontology in relation to the methods adhered to while completing animal work, but I think a deontological approach would also have us say that animal research is therefore moral in purpose because it results from adherence to these values.

For these reasons I would say that our society views animal experimentation as moral from not just one, but a multitude of ethical approaches, and it is deeply interwoven with other highly moral aspects of our society. Humans have a history of evolving societal views on morality, and society has undergone radical change to abolish what were once commonplace practices (e.g., slavery). However I would hesitate to predict such a change in regards to the moral views on animal experimentation due to our desire to prolong and improve our quality of life, feelings of selfworth and superior abilities as a species, and its connection with other things we believe to be moral and good.

M. Dodd is a PhD candidate studying at McMaster University. 


\section{Response to Comments - Article \#2}

While both Dodd and Farrar raise a number of valid points, they both seem to have misinterpreted or have misconstrued a number of my original arguments; as such, I will attempt to clarify my points further. First and foremost, it is important to recognize that while I do not necessarily agree with the points raised by those who protest animal use in research, I have tried to openly state and confront their more common arguments and positions. As such, I have attempted to directly address the issues that such groups raise and illustrate that, by following their reasoning, animal use in all aspects of life is unavoidable.

Dodd's response largely argues that the "ends justify the means" and uses the classical example of animals in medical research. This approach, as I had stated, does nothing to address the concerns raised by animal rights supporters as such medical advancements (drugs, therapies, etc.) are simply argued to be the fruit of the poisoned tree. Dodd focuses on the benefits such advancements provide society however, those in support of animal rights would be quick to highlight that this reasoning is fundamentally flawed, as said advancements come at the cost of performing (supposedly) immoral acts. Dodd's continued statements fail to address this and instead side step the issue with discussions of the benefits such work offers to society.

A more direct way to respond to this argument posed by animal rights supporters is to address that any animal with a "saving quality" would need to be exempt from all (ie: not just research) misuse, which is impractical and rarely argued for by such groups. This point opens the door to my initial statements on specism which was misinterpreted by Dodd. When referring to specism I was not comparing humans to other animals, rather I was comparing different groups of animals to one another. I had attempted to illustrate that animal rights groups will often fight against vertebrate research (eg. "cute and cuddly" animals such as rabbits) but do virtually nothing to protect numerous invertebrates (eg. "ugly" cockroaches). If both animals have the same "saving quality" (eg. learning and memory, perception of pain, etc.) then morally they should both be excluded from research. I illustrate that this is not the case and that following such ideals is not practical or possible.

Dodd closes by exemplifying mankind's ignorance and naivety with moral concerns with a reference to slavery. If centuries of firm belief can be incorrect (and subsequently changed) this example only highlights that our current view of animal rights may indeed be incorrect. Following this, Dodd suggests that such a change would be hampered by our desire for longevity and quality of life, thus suggesting that one's greed and selfishness would impair our moral compass. Once again this emphasizes that our current stance may be incorrect, as moral decisions should not be impacted by personal advancement or greed.

Farrar's response interprets my initial article as suggesting that animals are our moral equals, which is incorrect. I do strongly argue that all animals should be treated equally, regardless of their supposed importance as many "lesser" animals possess qualities suggested to be of moral consideration in "higher" animals. I do not however argue that animals are equal to that of humans. Unfortunately, Farrar focuses his response on this misinterpretation as he finds the complications arising from moral equality to be deeply dissatisfying. He then proceeds to fabricate a philosophical framework which offers a more comfortable environment.

Farrar discusses animal rights and focuses on knowledge and freedom of a subject in question. In doing so he suggests that animals lack moral knowledge, leading to the position that this excludes them from having rights worthy of consideration by humans. This line of reasoning should be reviewed with careful scrutiny, as its implications are widespread. First, this argumentum ad ignorantiam approach excludes the possibility that animals do in fact have the capacity to possess this idea of "knowledge". Our inability to detect and measure this self-awareness does not rule out the possibility that it is there. Quite simply, lack of evidence does not constitute proof of nonexistence. Indeed some animals are known to act in ways that could be considered moral, showing self-restraint, responsibility and compassion. ${ }^{i}$ Would a dog warning a stranger of imminent danger or dragging a child out from a burning building not be a moral act? If animals may act as moral agents would it not be better to air on the side of caution rather than blindly assume that all animals are completely instinctive and deprive them of moral rights?

Secondly, the notion that knowledge of rights is a requirement for moral consideration directly calls into question the rights of those who have an impaired capacity of such knowledge. If this knowledge is indeed an absolute requirement then those individuals without such knowledge - children, infants, those with cognitive deficits, etc. - would be deemed to be undeserving of moral consideration. Thankfully society at large does not agree with this standpoint, as those individuals do in fact have legal rights and by extension are also granted moral rights. The question of where to draw the line quickly becomes apparent and leads to further debate best left to other discussions.

Despite these disagreements, I fully agree with Farrar's assessment that as moral agents we should feel obligated to consider animal welfare. Interestingly, despite radically different approaches we reach a similar end point in that our focus should be that of how animals are treated. Combined with Dodd's comments it is refreshing to see a number of supporters (albeit for different reasons) for animal use in research. If nothing else, we can agree that animal use in research should continue. 